\title{
BBCIC Research Network Analysis of First-Cycle Prophylactic G-CSF Use in Patients Treated With High-Neutropenia Risk Chemotherapy
}

Pamala A. Pawloski, PharmD, BCOP'; Cara L. McDermott, PharmD, $\mathrm{PhD}^{2}$; James H. Marshall, MPH${ }^{3}$; Vanita Pindolia, PharmD, MBA ${ }^{4}$; Catherine M. Lockhart, PharmD, $\mathrm{PhD}^{2}$; Catherine A. Panozzo, $\mathrm{PhD}^{3}$; Jeffrey S. Brown, $\mathrm{PhD}^{3}$; and Bernadette Eichelberger, PharmD ${ }^{2}$

\begin{abstract}
Background: Chemotherapy-induced febrile neutropenia (FN) is prevented or minimized with granulocyte colony-stimulating factors (GCSFs). Several G-CSF biosimilars are approved in the United States. The Biologics and Biosimilars Collective Intelligence Consortium $(\mathrm{BBClC})$ is a nonprofit initiative whose objective is to provide scientific evidence on real-world use and comparative safety and effectiveness of biologics and biosimilars using the $\mathrm{BBCIC}$ distributed research network (DRN). Patients and Methods: We describe real-world G-CSF use in patients with breast or lung cancer receiving first-cycle chemotherapy associated with high FN risk. We assessed hospitalizations for FN, availability of absolute neutrophil counts, and G-CSF-induced adverse events to inform future observational comparative effectiveness studies of G-CSF reference products and their biosimilars. A descriptive analysis of 5 participating national health insurance plans was conducted within the BBCIC DRN. Results: A total of 57,725 patients who received at least one G-CSF dose were included. Most (92.5\%) patients received pegfilgrastim. FN hospitalization rates were evaluated by narrow $(<0.5 \%)$, intermediate (1.91\%), and broad (2.99\%) definitions. Anaphylaxis and hyperleukocytosis were identified in $1.15 \%$ and $2.28 \%$ of patients, respectively. This analysis provides real-world evidence extracted from a large, readily available database of diverse patients, characterizing G-CSF reference product use to inform the feasibility of future observational comparative safety and effectiveness analyses of G-CSF biosimilars. We showed that the rates of FN and adverse events in our research network are consistent with those reported by previous small studies. Conclusions: Readily available BBCICDRN data can be used to assess G-CSF use with the incidence of FN hospitalizations. Insufficient laboratory result data were available to report absolute neutrophil counts; however, other safety data are available for assessment that provide valuable baseline data regarding the effectiveness and safety of G-CSFs in preparation for comparative effectiveness studies of reference G-CSFs and their biosimilars.
\end{abstract}

J Natl Compr Canc Netw, doi: 10.6004/jnccn.2021.7027 Published online August 16, 2021

\footnotetext{
${ }^{1}$ HealthPartners Institute, Bloomington, Minnesota; ${ }^{2}$ Biologics and Biosimilars Collective Intelligence Consortium, Alexandria, Virginia; ${ }^{3}$ Department of Population Medicine, Harvard Medical School and Harvard Pilgrim Health Care Institute, Boston, Massachusetts; and ${ }^{4}$ Henry Ford Health System, Detroit, Michigan.
}

\section{Background}

Prophylaxis with the recombinant human granulocyte colony-stimulating factors (G-CSFs) filgrastim and pegfilgrastim prevents chemotherapy-induced neutropenia; reduces febrile neutropenia (FN) risk and infectionrelated and early mortality; and allows higher relative chemotherapy dose intensity. ${ }^{1-5}$ Primary prophylaxis is recommended for all patients receiving chemotherapy associated with high $(>20 \%)$ FN risk and considered for use with chemotherapy associated with intermediate (10\%-20\%) FN risk. ${ }^{6-8}$ Overall reported FN rates are $17 \%$ in patients with early-stage breast cancer ${ }^{9}$ and $13.1 \%$ in patients with newly diagnosed breast, colorectal, lung, lymphoid, or ovarian cancer. ${ }^{10}$ However, with G-CSF primary prophylaxis, the FN rate is $<5 \%{ }^{9}$

Despite the high costs associated with G-CSF administration, use of G-CSFs is cost saving, and G-CSFs are a critical part of cancer therapy. ${ }^{11}$ Thus, biosimilar availability in the United States was anxiously awaited. In 2010, the United States enacted the Biologics Price Competition and Innovation Act of 2009 to establish an abbreviated regulatory approval pathway for biosimilars. ${ }^{12}$ The basic tenet of biosimilars is that they have no clinically meaningful differences from their reference products. ${ }^{13}$ However, critical issues associated with biosimilar use in oncology were identified. ${ }^{14}$ In addition to comparability to reference biologics, assurance of patient safety, and improved patient access, effective pharmacovigilance vital to ensuring ongoing biosimilar safety and effectiveness was noted. ${ }^{15,16}$ Healthcare providers and patients expressed concerns regarding safety. ${ }^{17-22}$ An NCCN survey identified challenges associated with biosimilar introduction into the clinic, and studies assessing safety and efficacy of biosimilars were deemed most important. ${ }^{18}$ Subsequently, ASCO and ESMO each issued guidance

See JNCCN.org for supplemental online content. 
regarding biosimilar filgrastim use and highlighted the need for pharmacovigilance with real-world evidence. ${ }^{23,24}$

As of May 2020, two filgrastim and three pegfilgrastim biosimilar products are available in the United States. ${ }^{13}$ Randomized controlled trials confirm their efficacy, tolerability, and safety compared with the reference products. ${ }^{25-28} \mathrm{~A}$ subsequent meta-analysis of clinical trials demonstrated no significant differences in the mean duration of severe neutropenia, absolute neutrophil count (ANC) nadir depth or time to ANC recovery, FN incidence, or safety. ${ }^{29}$ Data regarding G-CSF biosimilar use in real-world settings are maturing, and critical pharmacovigilance of these products depends on the understanding of their use and clinical impact. ${ }^{30,31}$ Similar clinical and safety outcomes of the G-CSF biosimilars compared with their reference products are reported. ${ }^{32-34}$ These studies are consistent with initial, small, retrospective, observational analyses demonstrating equivalence or noninferiority with the reference product regarding FN incidence. ${ }^{30,31}$

The Biologics and Biosimilars Collective Intelligence Consortium (BBCIC), a nonprofit public service initiative, is dedicated to providing scientific, real-world evidence on the use and comparative safety and effectiveness of biologics and biosimilars. ${ }^{35}$ The objective of this descriptive analysis was to evaluate real-world G-CSF reference product use by evaluating administrative data extracted from a large, diverse network to characterize real-world G-CSF reference product use in patients receiving first-cycle chemotherapy associated with high FN risk for breast or lung cancer in preparation for future comparative effectiveness studies with G-CSF biosimilars. This work will inform future observational comparative safety and effectiveness analyses of G-CSF biosimilars.

\section{Patients and Methods}

Study Design, Data Source, and Participating Sites This retrospective, incident user cohort study assessed our ability to identify and describe G-CSF administration, describe hospitalizations for FN events, and determine the availability of potential confounders. The BBCIC leverages FDA Sentinel Initiative infrastructure, including a distributed research network (DRN) with access to curated data formatted in the Sentinel Common Data Model (SCDM), and publicly available Sentinel analytic tools. ${ }^{36}$ The BBCIC DRN includes insurance claims data from 5 health plans: Aetna (via Healthagen), Harvard Pilgrim Health Care (HPHC), Anthem (via HealthCore), HealthPartners, and Kaiser Permanente Washington. The Institutional Review Boards at HPHC for the BBCIC DRN and each health plan determined that the analysis did not meet the definition of human subjects research.

\section{Study Population}

Adults aged $\geq 18$ years with newly diagnosed breast or lung cancer who received at least one G-CSF dose between January 1, 2008, and September 30, 2015, were included in the analysis. Because the first G-CSF biosimilar was not approved in the United States until September 2015, biosimilar G-CSF use was not included. A minimum of 1 inpatient or 2 outpatient claims at least 30 days apart for breast or lung cancer with ICD-9 codes $174 . x-175 . x$ or 162.x-165.x, respectively, before the index G-CSF dispensing (index date) were required for study inclusion. Histology codes were not assessed; therefore, we refer to patients as having lung cancer, but treatment with topotecan implies that included patients had small cell lung cancer. This is based on clinical guidelines indicating that topotecan is appropriate for small cell lung cancer and not non-small cell lung cancer. ${ }^{37,38}$ Patients were required to be continuously enrolled in a participating health plan with both medical and drug coverage for at least 183 days before the index date, allowing coverage gaps up to 45 days (Figure 1).

Patients were excluded if they had any claim within 183 days before the index date for care in a skilled nursing facility or hospice care, a second cancer diagnosis identified by ICD-9 codes 140.x-195.x or 200.x-209.x, excluding the aforementioned breast cancer and lung cancer codes for study inclusion. Other exclusion criteria were claims for conditions associated with neutropenia, such as bone marrow or stem cell transplant (CPT codes 38230, 38231, 38240, 38241, 38242), a diagnosis of HIV/AIDS (ICD-9CM codes 042-044, 795.1, V08), or other non-oncologyrelated neutropenia (ICD-9-CM code 288.0).

\section{Exposures}

Chemotherapy regimens were limited to those associated with high FN risk and defined by the combinations of drug claims and/or dates of service for medication administration observed in each cycle (Table 1). The index date was defined as the first identified claim for G-CSF during the study period (Figure 1). Patients were required to have at least one outpatient claim for G-CSF on or before 2 days after the end of chemotherapy administration during the first cycle of treatment. The analysis was limited to G-CSF administered within the first 2 days after receipt of chemotherapy. Claims observed 3 to 14 days after chemotherapy administration were categorized as G-CSF treatment of neutropenia. Breast cancer treatment regimens were 1 day in length, and the lung cancer regimen was 5 days in length. Thus, chemotherapy was administered on day 1 for breast cancer and on day 1 and once daily for the following 4 days for lung cancer.

G-CSF exposures were classified as filgrastim, pegfilgrastim, and tbo-filgrastim. Pegfilgrastim administration was defined as a single injection. Filgrastim and 


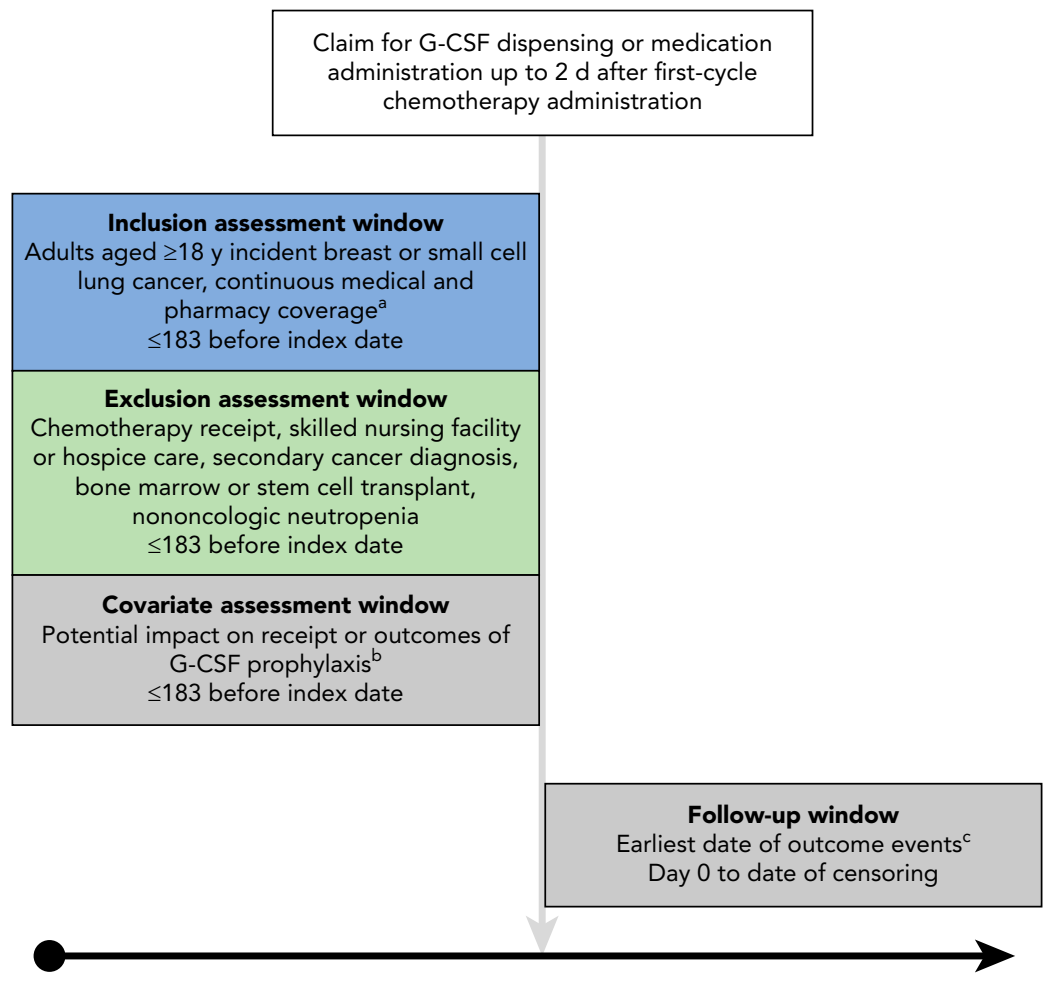

Figure 1. Exposure-based cohort entry after application of exclusion criteria.

Abbreviation: G-CSF, granulocyte colony-stimulating factor.

${ }^{a}$ As many as 45-day gaps in medical or pharmacy enrollment were allowed.

${ }^{\text {b}}$ See supplemental eAppendix 3.

'Death, end of enrollment, outcome adverse event (inpatient diagnosis febrile neutropenia, severe neutropenia, or combined safety outcome), treatment with next chemotherapy cycle, or new chemotherapy regimen.

tbo-filgrastim exposures were stratified into 2 groups: $<6$ injections and $\geq 6$ injections. National Drug Codes and HCPCS procedure codes were used to identify G-CSF exposures for analysis and are available in supplemental eAppendix 1 (available with this article at JNCCN.org).

Follow-up began the day the first G-CSF exposure of interest was administered or dispensed and continued until the first occurrence of (1) health plan disenrollment, (2) the study end date, (3) the end of the 21-day exposure episode, or (4) a study outcome. For each eligible patient, only the first incident exposure episode during the study period was considered.

\section{Outcomes}

In order to characterize the outcome and identify the most appropriate definition of $\mathrm{FN}$ for future studies, the primary outcome was identification of inpatient FN diagnoses during the first treatment cycle using ICD-9-CM codes in any position based on the following definitions: (1) narrow: a diagnosis of neutropenia (288.0x) and fever (780.6) on the

\section{Table 1. High-FN-Risk Chemotherapy Regimens for Breast and Small Cell Lung Cancers}

\begin{tabular}{|c|c|}
\hline Cancer Therapy & Regimen \\
\hline $\begin{array}{l}\text { Breast: docetaxel + trastuzumab } \\
\text { (metastatic or relapsed) }\end{array}$ & $\begin{array}{l}\text { Docetaxel, } 80-100 \mathrm{mg} / \mathrm{m}^{2} \text { IV day 1, cycled every } 21 \mathrm{~d} \text { or } 35 \mathrm{mg} / \mathrm{m}^{2} \text { IV days } 1,8 \text {, and } 15 \text { (weekly) } \\
\text { Trastuzumab, } 8 \mathrm{mg} / \mathrm{kg} \text { IV day } 1 \text {, followed by } 6 \mathrm{mg} / \mathrm{kg} \text { IV every } 21 \mathrm{~d} \text { or } 4 \mathrm{mg} / \mathrm{kg} \text { IV day } 1, \\
\text { followed by } 2 \mathrm{mg} / \mathrm{kg} \text { IV weekly }\end{array}$ \\
\hline Breast: dose-dense AC followed by T (adjuvant) & $\begin{array}{l}\text { Doxorubicin, } 60 \mathrm{mg} / \mathrm{m}^{2} \text { IV day } 1 \text {, cycled every } 14 \mathrm{~d} \text { for } 4 \text { cycles } \\
\text { Cyclophosphamide, } 600 \mathrm{mg} / \mathrm{m}^{2} \text { IV day } 1 \text {, cycled every } 14 \mathrm{~d} \text { for } 4 \text { cycles } \\
\text { Followed by paclitaxel, } 175 \mathrm{mg} / \mathrm{m}^{2} \text { by } 3 \text {-h IV infusion day } 1 \text {, cycled every } 14 \mathrm{~d} \text { for } 4 \text { cycles }\end{array}$ \\
\hline Breast: TAC (adjuvant) & $\begin{array}{l}\text { Docetaxel, } 75 \mathrm{mg} / \mathrm{m}^{2} \text { IV day } 1 \text {, cycled every } 21 \mathrm{~d} \text { for } 6 \text { cycles } \\
\text { Doxorubicin, } 50 \mathrm{mg} / \mathrm{m}^{2} \text { IV day } 1 \text {, cycled every } 21 \mathrm{~d} \text { for } 6 \text { cycles } \\
\text { Cyclophosphamide, } 500 \mathrm{mg} / \mathrm{m}^{2} \text { IV day } 1 \text {, cycled every } 21 \mathrm{~d} \text { for } 6 \text { cycles }\end{array}$ \\
\hline Small cell lung cancer & Oral topotecan, $2.3 \mathrm{mg} / \mathrm{m}^{2} / \mathrm{d}$ or IV topotecan, $1.5 \mathrm{mg} / \mathrm{m}^{2} / \mathrm{d}$ on days $1-5$ every $3 \mathrm{wk}$ \\
\hline
\end{tabular}

Chemotherapy regimens are based on NCCN Clinical Practice Guidelines in Oncology (NCCN Guidelines) for Breast Cancer, Version 1.2015, and NCCN

Guidelines for Small Cell Lung Cancer, Version 2.2014; to view the most recent versions, visit NCCN.org.

Abbreviations: A, doxorubicin; C, cyclophosphamide; FN, febrile neutropenia; IV, intravenous; T, taxane. 
same day; (2) intermediate: neutropenia (288.0x) only; and (3) broad: neutropenia (288.0x) or fever (780.6) or infection (001.x-139.x). ${ }^{30,31,39,40}$

Secondary outcomes included the incidence of severe neutropenia (ANC $<0.5 / \mathrm{mm}^{3}$ ) and a safety event (anaphylaxis, glomerulonephritis, capillary leak syndrome, hyperleukocytosis, and splenic rupture incidence). All adverse events were defined using ICD-9-CM codes, CPT codes, and Logical Observation Identifiers Names and Codes (supplemental eAppendix 2). Outcome events were assessed through the earliest of death, end of health plan enrollment, a safety outcome event, treatment with the next chemotherapy cycle, or a switch to another chemotherapy treatment regimen.

\section{Covariates}

We identified baseline covariates in the 183 days before the index date potentially associated with G-CSF receipt or study outcomes (supplemental eAppendix 3). Standard demographic covariates include age (grouped as 18-49, 50-64, 65-79, and $\geq 80$ years), sex, and calendar year. A combined comorbidity score derived from the Charlson and Elixhauser measures was calculated for each study subject. ${ }^{41}$

\section{Analyses}

A distributed data approach utilizing the SCDM Cohort Identification and Descriptive Analysis tool (version 5.0.3) was used for this analysis. ${ }^{42,43}$ Only aggregate data were shared outside of each data partner site for analysis and reporting. To calculate the mean of specific data (eg, age of study subjects), ad hoc programs were distributed to evaluate individual-level data, with final aggregated results provided. The frequencies of new G-CSF users in the breast and lung cancer cohorts were assessed. The distribution and mean number of days of G-CSF use and the frequency of ANC data were estimated. The prevalence of each exposure category and incidence of each outcome (FN hospitalizations, severe neutropenia [ANC $<0.5$ / $\mathrm{mm}^{3}$ ], and anaphylaxis) were stratified by age group, sex, and year and reported separately for breast and lung cancers. G-CSF exposures $\geq 3$ days after the end of chemotherapy administration were reported separately for each diagnosis. Covariate frequencies and percentages (or means and standard deviations) were estimated in each cohort.

Frequencies of FN events were reported according to the primary and varying definitions (Table 2), crude incidences, and associated 95\% confidence intervals. Frequencies of adverse events in G-CSF users in each cancer cohort were also reported. Incidences were defined as the ratio of first adverse events divided by the total chemotherapy cycles during the study period and estimated as overall and stratified by the predefined age groups, year

\begin{tabular}{|c|c|c|}
\hline & Frequency & $(95 \% \mathrm{Cl})$ \\
\hline \multicolumn{3}{|l|}{ FN events } \\
\hline Broad definition & $2.99 \%$ & $(2.5-3.57)$ \\
\hline Intermediate definition & $1.91 \%$ & $(1.53-2.38)$ \\
\hline Narrow definition & $<0.5 \%$ & NC \\
\hline Anaphylaxis & $1.15 \%$ & $(0.86-1.54)$ \\
\hline Hyperleukocytosis & $2.28 \%$ & $(1.86-2.79)$ \\
\hline $\begin{array}{l}\text { Combined outcome of rare AEs: } \\
\text { glomerulonephritis, capillary leak } \\
\text { syndrome, splenic rupture }\end{array}$ & $<0.5 \%$ & $\mathrm{NC}$ \\
\hline
\end{tabular}

Abbreviations: AE, adverse event; FN, febrile neutropenia; G-CSF, granulocyte colony-stimulating factor; NC, not calculated.

${ }^{a}$ Breast or lung cancer diagnosis occurred before index G-CSF exposure.

of G-CSF initiation, and sex. Per the Sentinel System's standard operating procedures, all data elements in the SCDM undergo a rigorous quality assurance and curation process. ${ }^{44,45}$

\section{Results}

\section{Baseline Characteristics}

We identified 38,721 unique patients with breast cancer and 19,004 unique patients with lung cancer who received at least one dose of G-CSF (Table 3). The average ages of subjects with breast and lung cancer were 55.1 and 63.7 years, respectively. Most (83.1\%) patients with breast cancer were aged $<65$ years, and nearly all (98.9\%) were women, whereas $44.2 \%$ with lung cancer were aged 50 to 64 years, and approximately half (51\%) were women. The average combined comorbidity score was lower in the breast cancer cohort (mean [SD], 4.2 [2.9]). Baseline covariates potentially affecting G-CSF receipt or outcomes associated with G-CSF therapy are available in supplemental eAppendix 3. Nearly half of all patients had a history of metastatic disease (Table 3). Of those, 9.3\% with breast cancer and $22.4 \%$ with lung cancer had metastases that spread to the bone. Both groups had previous receipt of a bone-modifying agent such as zoledronic acid, which could indicate confounding if bone pain was included as a secondary outcome.

Of those who received G-CSF, 4,896 met our criteria for analysis (4,745 with breast cancer and 151 with lung cancer) (Table 4). Most (99\%) patients with breast cancer and more than half (57\%) with lung cancer were women, and nearly all (92\%) exposures were due to pegfilgrastim. Filgrastim administration was low across users, and, because of small sample sizes, administration stratified by $<6$ days and $\geq 6$ days after chemotherapy administration is not presented. The primary outcome, rate of 


\begin{tabular}{|c|c|c|}
\hline Characteristic & $\begin{array}{l}\text { Breast Cancer } \\
\mathrm{n}(\%)\end{array}$ & $\begin{array}{l}\text { Lung Cancer } \\
\text { n (\%) }\end{array}$ \\
\hline Unique patients, $\mathrm{n}$ & 38,721 & 19,004 \\
\hline Age, mean [SD], y & $55.1[10.9]$ & $63.7[10.9]$ \\
\hline $18-49$ & $12,767(33.0)$ & $1,956(10.3)$ \\
\hline $50-64$ & $19,381(50.1)$ & $8,408(44.2)$ \\
\hline $65-79$ & $5,988(15.5)$ & $7,385(38.9)$ \\
\hline$\geq 80$ & $585(1.5)$ & $1,255(6.6)$ \\
\hline Female sex & 38,307 (98.9) & $9,690(51)$ \\
\hline $\begin{array}{l}\text { Combined comorbidity score, } \\
\text { mean }[S D]\end{array}$ & $4.2[2.9]$ & $6.4[3.0]$ \\
\hline \multicolumn{3}{|l|}{$\begin{array}{l}\text { Baseline covariates } \\
\text { (183 d before index exposure) }\end{array}$} \\
\hline Anaphylaxis & $1,344(3.5)$ & $1,031(5.4)$ \\
\hline Anemia & $6,945(17.9)$ & $7,234(38.1)$ \\
\hline Arthritis & $1,294(3.3)$ & $873(4.6)$ \\
\hline Bone marrow $/ \mathrm{SCT}^{\mathrm{a}}$ & $<10(<0.1)$ & $<10(<0.1)$ \\
\hline Bone pain & $6,141(15.9)$ & $3,659(19.3)$ \\
\hline Cancer-related radiation & $3,065(7.9)$ & $6,699(35.3)$ \\
\hline Capillary leak syndrome & $53(0.1)$ & $20(0.1)$ \\
\hline Congestive heart failure & $1,057(2.7)$ & $1,742(9.2)$ \\
\hline COPD & $5,096(13.2)$ & $10,149(53.4)$ \\
\hline Glomerulonephritis & $23(0.1)$ & $24(0.1)$ \\
\hline HIV/AIDS $^{a}$ & $40(0.1)$ & $65(0.3)$ \\
\hline Hyperleukocytosis & $742(1.9)$ & $1,284(6.8)$ \\
\hline Kidney disorder & $339(0.9)$ & $270(1.4)$ \\
\hline Latex allergy & $188(0.5)$ & $44(0.2)$ \\
\hline Severe liver impairment & $836(2.2)$ & $717(3.8)$ \\
\hline Lumpectomy/Mastectomy & $22,561(58.3)$ & $368(1.9)$ \\
\hline Metastatic cancer & $18,450(47.6)$ & $8,637(45.4)$ \\
\hline Other cancer diagnosis ${ }^{a}$ & $7,344(19)$ & $9,683(51)$ \\
\hline Neutropenia & $4,949(12.8)$ & $3,217(16.9)$ \\
\hline Peptic ulcer disease & $225(0.6)$ & $376(2.0)$ \\
\hline Poor nutritional status & $3,307(8.5)$ & $2,286(12.0)$ \\
\hline Splenic rupture & $11(<0.1)$ & $12(0.1)$ \\
\hline Recent surgery/wounds & $25,131(64.9)$ & $4,506(23.7)$ \\
\hline Thyroid disorder & $7,096(18.3)$ & $3,113(16.4)$ \\
\hline Antibiotics & $21,231(54.8)$ & $11,647(61.3)$ \\
\hline Endocrine drug products & $5,627(14.5)$ & $1,523(8.0)$ \\
\hline $\begin{array}{l}\text { BMAs (eg, zoledronic acid, } \\
\text { bisphosphonates) }\end{array}$ & $1,342(3.5)$ & $666(3.5)$ \\
\hline $\begin{array}{l}\text { Other chemotherapy } \\
\text { (breast/lung) }\end{array}$ & $1,279(3.3)$ & $8,040(42.3)$ \\
\hline $\begin{array}{l}\text { Other chemotherapy } \\
\text { (not breast/not lung) }\end{array}$ & $1,486(3.8)$ & $1,678(8.8)$ \\
\hline
\end{tabular}

Based on FDA Sentinel Initiative reporting tool functionality, any values $<10$ were rounded to 10 , and totals are reported as approximate values. Abbreviations: BMA, bone-modifying agent; $C O P D$, chronic obstructive pulmonary disease; G-CSF, granulocyte colony-stimulating factor; SCT, stem cell transplant.

aPatients excluded from study analysis.

\begin{tabular}{|c|c|c|c|}
\hline Characteristic & $\begin{array}{l}\text { Breast } \\
\text { Cancer }\end{array}$ & $\begin{array}{l}\text { Lung } \\
\text { Cancer }\end{array}$ & Combined \\
\hline \multicolumn{4}{|l|}{ Demographics } \\
\hline Unique patients, $\mathrm{n}$ & 4,745 & 151 & 4,896 \\
\hline \multicolumn{4}{|l|}{ Mean age, $n$} \\
\hline $18-49 y$ & 1,676 & $<10$ & NC \\
\hline $50-64$ y & 2,366 & 70 & 2,436 \\
\hline $65-79$ y & 675 & 64 & 739 \\
\hline$\geq 80 y$ & 28 & $<10$ & NC \\
\hline Female sex, $\%$ & 99.32 & 56.95 & 98.02 \\
\hline \multicolumn{4}{|c|}{ G-CSF exposures (total) } \\
\hline Filgrastim, \% & 7.17 & 27.15 & 7.78 \\
\hline Pegfilgrastim, \% & 92.52 & 72.19 & 91.89 \\
\hline Tbo-filgrastim, \% & 0.31 & 0.66 & 0.33 \\
\hline
\end{tabular}

Breast or lung cancer diagnosis occurred before index G-CSF exposure. Abbreviations: G-CSF, granulocyte colony-stimulating factor; NC, not calculated due to small cell counts.

hospitalization for a diagnosis of FN, varied greatly across the neutropenia definitions previously provided. Narrow $(<0.5 \%)$, intermediate $(1.91 \%)$, and broad $(2.99 \%)$ definitions are described in Table 2. Secondary outcomes were anaphylaxis (1.15\%); hyperleukocytosis $(2.28 \%)$; and a combined rare event outcome of glomerulonephritis, capillary leak syndrome, and splenic rupture $(<0.14 \%)$. Laboratory data are not entered into the databases of 2 of the 5 participating research partners. Therefore, ANC $<500 / \mathrm{mm}^{3}$ was identified in $<10$ patients, and ANC $\geq 500 / \mathrm{mm}^{3}$ was identified in only 48 patients (data not shown). Bone pain was attributed to $1 \%$ of eligible patients. When FN events were assessed by age, there was wide variation between definitions, with too few events identified for the narrow definition or for those aged $\geq 80$ years (data not shown).

\section{Discussion}

We characterize and describe real-world use of G-CSFs for FN prophylaxis in patients with breast or lung cancer in the BBCIC DRN, including availability of key data elements and identification of potential confounders. This analysis will inform future observational comparative safety and effectiveness analyses of G-CSF biosimilar use. We assessed the ability to measure the incidence of hospitalizations for FN, ANC $<0.5 / \mathrm{mm}^{3}$, depth of ANC nadir, time to ANC recovery, and changes from baseline ANC. Specifically, we analyzed G-CSF administration and availability of ANC measures across sites. The breast cancer cohort was expectedly younger and mostly women; those with lung cancer were older, and half of them were women. Incident FN counts using broad, 
intermediate, or narrow definitions were consistent with those in previous reports..$^{30,31}$

Schwartzberg et $\mathrm{al}^{30}$ evaluated FN rates in 3,297 patients with solid tumors. Roughly one-third had previous G-CSF use. Reference G-CSF was compared with the biosimilar, filgrastim-sndz. FN defined as fever/neutropenia, neutropenia/infection, or neutropenia/infection/ fever occurred in $0.9 \%, 1.7 \%$, and $0.3 \%$, respectively. Administrative codes seemed to be similar despite our population being slightly younger (55.1 and 63.7 years for patients with breast and lung cancer, respectively vs 64.7 years) among those receiving reference filgrastim. Baseline comorbidity scores were similar at 5.8 versus 4.2 and 6.4 in breast and lung cancer, respectively, in our study, and safety outcomes were not evaluated.

Douglas et $\mathrm{al}^{31}$ compared filgrastim with filgrastimsndz in 88 patients with any G-CSF use and Medicare Advantage coverage from October 1, 2015, to September 30 , 2016. FN incidence associated with the reference G-CSF was based on broad (neutropenia or infection, $3.4 \%$ ) and narrow (neutropenia and infection, $1.1 \%$ ) definitions. The population was older (mean age, 71.3 years) and $55.7 \%$ were women. Safety was measured using a combined composite score for splenic rupture, acute respiratory syndrome, serous allergic reaction, capillary leak syndrome, thrombocytopenia, leukocytosis, cutaneous vasculitis, and bone and muscle ache, which cannot be compared with our combined safety score due to included variables. Combined neutropenia and infection codes were similar between studies: $1.7 \%$ for Schwartzberg et $\mathrm{a}^{30}$ and $1.1 \%$ for Douglas et $\mathrm{al}^{31}$ and fever and neutropenia occurred in $1 \%$ in our study and $0.9 \%$ in the study by Schwartzberg et al. ${ }^{30}$

The unavailability of ANC data is consistent with other analyses using administrative data. ${ }^{30,31}$ This does not preclude our ability to identify and report FN events. However, ANC data could provide insight into the degree of severe neutropenia. Future studies may include new partners capturing ANC data. As expected, anaphylaxis, bone pain, hyperleukocytosis, and combined rare event rates were low and consistent with other findings. ${ }^{32}$ We identified $1 \%$ of patients with bone pain; however, this is low based on clinical studies reporting rates of $19 \%$ and $24.7 \%{ }^{32,46}$ Because a specific ICD-9 code is lacking, bone pain is likely underreported or attributed to other codes. Furthermore, patients using bone-modifying agents at baseline confound our ability to attribute bone pain to G-CSFs, and the inclusion of bone pain as a safety event is limited. Similarly, the low incidence of hyperleukocytosis associated with our findings is likely due to the limited laboratory data available in our database.

This study has a number of strengths, including readily available, standardized, curated data across several large health insurance plans and integrated health systems representing a large, diverse population. The retrospective study design limits our analysis to exposures, covariates, and outcomes captured in claims data when a patient uses medical and pharmacy benefits. The occurrence of FN events occurring outside of health systems contributing data could be unreported; however, the data are administrative claims filed, regardless of the site of care, and we expect the number of missing claims to be low. ${ }^{39,47,48}$ It is possible that FN was not the diagnosis assigned to the hospitalization and was therefore not captured in the administrative data. Furthermore, this analysis was designed using NCCN Guidelines that are no longer the current guidelines available for clinical practice, and outcomes may vary with updated guidelines. Because administrative data do not include dose and administration details, we cannot guarantee that patients received the exact chemotherapy regimen listed in the guidelines; however, we are certain the patients received the drug(s) listed in each regimen.

This analysis was limited to chemotherapy regimens associated with high FN risk to eliminate the ambiguity of available administrative claims for the use of G-CSF prophylaxis related to chemotherapy associated with intermediate FN risk and therefore the result of clinical decision-making. The inclusion of intermediate FN risk is of great interest and concern but is beyond the scope of this initial analysis and will be a focus of future work involving biosimilars. The administration of intermediate-risk chemotherapy and G-CSF prophylaxis extends beyond chronologic age and the presence of comorbidities to include individual patient performance status. ${ }^{4-52}$ The use of administrative data is limited by the lack of clinical information such as the degree of liver dysfunction or neutropenia or performance status. Because physiologic age rather than chronologic age better predicts clinical status, this is likely the reason for the importance of performance status when determining chemotherapy administration. Another key factor that potentially plays a role in the determination of performance status is frailty. Frailty is known to be predictive of patient toxicity during chemotherapy, regardless of chronologic age.$^{53}$ It is also not characterized or quantified by existing administrative codes. Studies to identify and validate measures of frailty and performance status using administrative data are evolving. ${ }^{54-57}$ An association between claims-based frailty indices and clinical outcomes has been demonstrated.$^{58}$ This work using Medicare claims data has recently expanded into other healthcare databases; however, there remains a need for validation in administrative data from large insurers. Notably, the choice of claims-based measures can influence the identification of frailty. ${ }^{59}$ Thus, critical evaluation of these measures in new data sources is warranted before it can be readily used for research studies. Use of these measures is of great interest, and we anticipate incorporating them in 
future work in this area; however, the magnitude of efforts to assess and validate these measures in a new data source extends beyond the scope of the present work. As with all observational studies, the analysis was limited in its ability to control for all sources of potential bias. Exposures, inclusions, and covariates may have been misclassified due to imperfect algorithms used to identify them. However, based on the comparable event rates determined by this analysis, we believe that if misclassification occurred, it was at a very low rate.

\section{Conclusions}

This analysis represents one of the first large-scale assessments of G-CSF use across a diverse population of patients receiving chemotherapy for breast or lung cancer with high neutropenia risk, showing data utility and ability to identify outcomes consistent with previous smaller analyses. It also provides valuable information that will contribute to future observational comparative safety and effectiveness studies of G-CSFs and their biosimilars.

\section{Acknowledgments}

The authors acknowledge Sarah Malek, project manager, and Katie King, research assistant, at Harvard Pilgrim Healthcare Institute (HPHCI) for their support. We thank the BBCIC G-CSF Research Team: Bernadette Eichelberger (BBCIC), Catherine M. Lockhart (BBCIC), Cara L. McDermott (BBCIC), Pamala A. Pawloski (HealthPartners), Vanita Pindolia (HFHS), Jeffrey S. Brown (HPHCI), Sarah Malek (HPHCI),
James H. Marshall (HPHCI), Catherine A. Panozzo (HPHCI), Brie Purcell (HPHCI), Jessica Sturtevant (HPHCI), Jessica Young (HPHCI), Jennifer Williams (Aetna), Angelika Manthripragada (formerly of Amgen), Kiraat D. Munshi (Express Scripts), Mohammed Alzahrani (Howard University), La'Marcus T. Wingate (Howard University), Victor Farutin (Momenta Pharmaceuticals), Edward Li (Sandoz Pharmaceuticals), and Gary C. Yee (University of Nebraska). We also thank Ann Harste and Mary Van Beusekom from HealthPartners Institute for their assistance with manuscript preparation and submission.

Submitted May 21, 2020; final revision received February 15, 2021; accepted for publication February 16, 2021.

Published online August 16, 2021

Author contributions: Study concept and design: Pawloski, Marshall, Pindolia, Panozzo, Brown, Eichelberger. Provision of study materials: Marshall, Brown. Acquisition and assembly of data: Marshall, Brown. Data analysis and interpretation: All authors. Manuscript preparation and final approval: All authors.

Disclosures: Dr. Pawloski has disclosed serving as a scientific partner of the Biologics and Biosimilars Collective Intelligence Consortium (BBCIC) and receiving financial support for the conduct of the work described in this article. The remaining authors have disclosed that they have not received any financial consideration from any person or organization to support the preparation, analysis, results, or discussion of this article.

Funding: Support for this work was provided by the BBCIC members.

Data availability statement: The primary data are under the full control of Harvard Pilgrim Health Care Institute, and we agree to allow the journal to review the data, if requested.

Correspondence: Pamala A. Pawloski, PharmD, BCOP, HealthPartners Institute Clinical Research, 295 Phalen Boulevard, MS41200F, St. Paul, MN 55130. Email: pamala.a.pawloski@healthpartners.com

\section{References}

1. Green MD, Koelbl H, Baselga J, et al. A randomized double-blind multicenter phase III study of fixed-dose single-administration pegfilgrastim versus daily filgrastim in patients receiving myelosuppressive chemotherapy. Ann Oncol 2003;14:29-35

2. Chan $A, F u$ WH, Shih $V$, et al. Impact of colony-stimulating factors to reduce febrile neutropenic events in breast cancer patients receiving docetaxel plus cyclophosphamide chemotherapy. Support Care Cancer 2011;19:497-504.

3. Elting LS, Xu Y, Chavez-MacGregor M, et al. Granulocyte growth factor use in elderly patients with non-Hodgkin's lymphoma in the United States: adherence to guidelines and comparative effectiveness. Support Care Cancer 2016;24:2695-2706.

4. Renner P, Milazzo S, Liu JP, et al. Primary prophylactic colony-stimulating factors for the prevention of chemotherapy-induced febrile neutropenia in breast cancer patients. Cochrane Database Syst Rev 2012;10:CD007913.

5. Kuderer NM, Dale DC, Crawford J, et al. Impact of primary prophylaxis with granulocyte colony-stimulating factor on febrile neutropenia and mortality in adult cancer patients receiving chemotherapy: a systematic review. J Clin Oncol 2007;25:3158-3167.

6. Smith TJ, Bohlke K, Lyman GH, et al. Recommendations for the use of WBC growth factors: American Society of Clinical Oncology clinical practice guideline update. J Clin Oncol 2015;33:3199-3212.

7. Crawford J, Caserta C, Roila F. Hematopoietic growth factors: ESMO clinical practice guidelines for the applications. Ann Oncol 2010;21(Suppl 5):v248-251.

8. Becker PS, Griffiths EA, Alwan L, et al. NCCN Clinical Practice Guidelines in Oncology: Hematopoietic Growth Factors. Version 2.2020. Accessed May 8,2020 . To view the most recent version, visit NCCN.org

9. Bacrie J, Laurans $M$, lorio $P$, et al. Febrile neutropenia in adjuvant and neoadjuvant chemotherapy for breast cancer: a retrospective study in

routine clinical practice from a single institution. Support Care Cancer 2018; 26:4097-4103

10. Pawloski PA, Thomas AJ, Kane S, et al. Predicting neutropenia risk in patients with cancer using electronic data. J Am Med Inform Assoc 2017; 24:e129-135.

11. The value of granulocyte colony stimulating factors in managing febrile neutropenia. Accessed May 8, 2020. Available at: https://www.ajmc.com/ view/the-value-of-granulocyte-colony-stimulating-factors-in-managingfebrile-neutropenia

12. Koyfman H. Biosimilarity and interchangeability in the Biologics Price Competition and Innovation Act of 2009 and FDA's 2012 Draft Guidance for Industry. Biotechnol Law Rep 2013;32:238-251.

13. U.S. Food \& Drug Administration. Biosimilar product information. Accessed May 8, 2020. Available at: https://www.fda.gov/drugs/ biosimilars/biosimilar-product-information

14. Hirsch BR, Lyman GH. Biosimilars: are they ready for primetime in the United States? J Natl Compr Canc Netw 2011;9:934-943.

15. Hirsch BR, Lyman GH. Will biosimilars gain momentum? J Natl Compr Canc Netw 2013;11:1291-1297.

16. Winckworth-Prejsnar K, Nardi EA, McCanney J, et al. Ensuring patient safety and access in cancer care. J Natl Compr Canc Netw 2017;15:1460-1464.

17. Roger SD, Mikhail A. Biosimilars: opportunity or cause for concern? J Pharm Pharm Sci 2007;10:405-410.

18. Zelenetz AD, Ahmed I, Braud EL, et al. NCCN Biosimilars White Paper: regulatory, scientific, and patient safety perspectives. J Natl Compr Canc Netw 2011;9(Suppl 4):S1-22.

19. McKinnon R, Ward M. Safety considerations of biosimilars. Aust Prescr 2016;39:188-189. 
20. Skingle D. Biosimilars: what do patients need to consider? RMD Open 2015;1:e000141.

21. Leonard E, Wascovich M, Oskouei $\mathrm{S}$, et al. Factors affecting health care provider knowledge and acceptance of biosimilar medicines: a systematic review. J Manag Care Spec Pharm 2019;25:102-112.

22. Greener M. Biosimilars: ensuring safety in the search for savings. Accessed May 8, 2020. Available at: https://wchh.onlinelibrary.wiley.com/doi/pdf/10. $1002 /$ psb. 1560

23. Tabernero J, Vyas M, Giuliani R, et al. Biosimilars: a position paper of the European Society for Medical Oncology, with particular reference to oncology prescribers. ESMO Open 2016;1:e000142.

24. Lyman GH, Balaban E, Diaz M, et al. American Society of Clinical Oncology statement: biosimilars in oncology. J Clin Oncol 2018;36:1260-1265.

25. Blackwell K, Semiglazov V, Krasnozhon D, et al. Comparison of EP2006, a filgrastim biosimilar, to the reference: a phase III, randomized, double-blind clinical study in the prevention of severe neutropenia in patients with breast cancer receiving myelosuppressive chemotherapy. Ann Oncol 2015;26: 1948-1953.

26. Harbeck N, Gascón P, Krendyukov A, et al. Safety profile of biosimilar filgrastim (Zarzio/Zarxio): a combined analysis of phase III studies. Oncologist 2018;23:403-409.

27. Yao HM, Ottery FD, Borema T, et al. PF-06881893 (Nivestym ${ }^{\text {TM }}$ ), a filgrastim biosimilar, versus US-licensed filgrastim reference product (USNeupogen ${ }^{\circledR}$ ): pharmacokinetics, pharmacodynamics, immunogenicity, and safety of single or multiple subcutaneous doses in healthy volunteers. BioDrugs 2019;33:207-220.

28. Waller CF, Ranganna GM, Pennella EJ, et al. Randomized phase 3 efficacy and safety trial of proposed pegfilgrastim biosimilar MYL-1401H in the prophylactic treatment of chemotherapy-induced neutropenia. Ann Hematol 2019;98:1217-1224

29. Botteri E, Krendyukov A, Curigliano G. Comparing granulocyte colonystimulating factor filgrastim and pegfilgrastim to its biosimilars in terms of efficacy and safety: a meta-analysis of randomised clinical trials in breast cancer patients. Eur J Cancer 2018;89:49-55.

30. Schwartzberg LS, Lal LS, Balu S, et al. Clinical outcomes of treatment with filgrastim versus a filgrastim biosimilar and febrile neutropenia-associated costs among patients with nonmyeloid cancer undergoing chemotherapy. J Manag Care Spec Pharm 2018;24:976-984.

31. Douglas AG, Schwab P, Lane D, et al. A comparison of brand and biosimilar granulocyte-colony stimulating factors for prophylaxis of chemotherapyinduced febrile neutropenia. J Manag Care Spec Pharm 2017;23:1221-1226.

32. Gascón P, Aapro M, Ludwig H, et al. Treatment patterns and outcomes in the prophylaxis of chemotherapy-induced (febrile) neutropenia with biosimilar filgrastim (the MONITOR-GCSF study). Support Care Cancer 2016; 24:911-925

33. Ludwig H, Gascón P, Bokemeyer $\mathrm{C}$, et al. Outcomes of chemotherapyinduced (febrile) neutropenia prophylaxis with biosimilar filgrastim (Zarzio $\left.{ }^{\circledR}\right)$ initiated "same-day" ( $<24$ h), "per-guidelines" (24-72 h), and "late" (>72 h): findings from the MONITOR-GCSF study. Support Care Cancer 2019;27:2301-2312.

34. Kamioner D, Fruehauf S, Maloisel F, et al. Study design: two long-term observational studies of the biosimilar filgrastim Nivestim ${ }^{\text {TM }}$ (Hospira filgrastim) in the treatment and prevention of chemotherapy-induced neutropenia. BMC Cancer 2013;13:547.

35. Biologics and Biosimilars Collective Intelligence Consortium (BBCIC). Accessed May 9, 2020. Available at: https://www.bbcic.org/

36. Platt R, Brown JS, Robb M, et al. The FDA Sentinel Initiative_-an evolving national resource. N Engl J Med 2018;379:2091-2093.

37. Ganti AKP, Loo BW Jr, Akerley W, et al. NCCN Clinical Practice Guidelines in Oncology: Small Cell Lung Cancer. Version 3.2020. Accessed May 9 2020. To view the most recent version, visit NCCN.org

38. Ettinger DS, Wood DE, Aisner DL, et al. NCCN Clinical Practice Guidelines in Oncology: Non-Small Cell Lung Cancer. Version 3.2020. Accessed May 9 , 2020. To view the most recent version, visit NCCN.org

39. Naeim A, Henk HJ, Becker L, et al. Pegfilgrastim prophylaxis is associated with a lower risk of hospitalization of cancer patients than filgrastim prophylaxis: a retrospective United States claims analysis of granulocyte colony-stimulating factors (G-CSF). BMC Cancer 2013;13:11.

40. Weycker D, Sofrygin O, Seefeld K, et al. Technical evaluation of methods for identifying chemotherapy-induced febrile neutropenia in healthcare claims databases. BMC Health Serv Res 2013;13:60.

41. Gagne JJ, Glynn RJ, Avorn J, et al. A combined comorbidity score predicted mortality in elderly patients better than existing scores. J Clin Epidemiol 2011;64:749-759

42. FDA Sentinel Initiative. The Sentinel routine querying system. Accessed May 9, 2020. Available at: https://www.sentinelinitiative.org/methodsdata-tools/routine-querying-tools/routine-querying-system

43. FDA Sentinel Initiative. The Sentinel routine querying system modification history. Accessed May 9, 2020. Available at: https://dev.sentinelsystem. org/projects/SENTINEL/repos/sentinel-routine-querying-tooldocumentation/browse/files/file019-typeall-modification.md

44. FDA Sentinel Initiative. Sentinel Initiative data quality review and characterization. Accessed May 9, 2020. Available at: https://www. sentinelinitiative.org/sentinel/data-quality-review-and-characterization

45. FDA Sentinel Initiative. Sentinel data quality assurance practices. Accessed May 9, 2020. Available at: https://www.sentinelinitiative.org/sentinel/data/ distributed-database-common-data-model/sentinel-data-qualityassurance-practices

46. Pawloski PA, Larsen M, Thoresen A, et al. Pegfilgrastim use and bone pain a cohort study of community-based cancer patients. J Oncol Pharm Pract 2016;22:423-429.

47. Henk HJ, Li X, Becker LK, et al. Comparative effectiveness of colonystimulating factors in febrile neutropenia prophylaxis: how results are affected by research design. J Comp Eff Res 2015;4:37-50.

48. Tan H, Cai Q, Agarwal S, et al. Impact of adherence to disease-modifying therapies on clinical and economic outcomes among patients with multiple sclerosis. Adv Ther 2011;28:51-61.

49. Baig H, Somlo B, Eisen M, et al. Appropriateness of granulocyte colonystimulating factor use in patients receiving chemotherapy by febrile neutropenia risk level. J Oncol Pharm Pract 2019;25:1576-1585.

50. Lyman $\mathrm{GH}$, Lyman $\mathrm{CH}$, Agboola O. Risk models for predicting chemotherapy-induced neutropenia. Oncologist 2005;10:427-437.

51. Lyman GH, Morrison VA, Dale DC, et al. Risk of febrile neutropenia among patients with intermediate-grade non-Hodgkin's lymphoma receiving CHOP chemotherapy. Leuk Lymphoma 2003;44:2069-2076.

52. Shayne M, Crawford J, Dale DC, et al. Predictors of reduced dose intensity in patients with early-stage breast cancer receiving adjuvant chemotherapy. Breast Cancer Res Treat 2006;100:255-262.

53. Ruiz J, Miller AA, Tooze JA, et al. Frailty assessment predicts toxicity during first cycle chemotherapy for advanced lung cancer regardless of chronologic age. J Geriatr Oncol 2019;10:48-54.

54. Salloum RG, Smith TJ, Jensen GA, et al. Using claims-based measures to predict performance status score in patients with lung cancer. Cancer 2011 117:1038-1048.

55. Kim DH, Schneeweiss S. Measuring frailty using claims data for pharmacoepidemiologic studies of mortality in older adults: evidence and recommendations. Pharmacoepidemiol Drug Saf 2014;23:891-901.

56. Kim DH, Schneeweiss S, Glynn RJ, et al. Measuring frailty in Medicare data: development and validation of a claims-based frailty index. J Gerontol A Biol Sci Med Sci 2018;73:980-987

57. Cuthbertson CC, Kucharska-Newton A, Faurot KR, et al. Controlling for frailty in pharmacoepidemiologic studies of older adults: validation of an existing Medicare claims-based algorithm. Epidemiology 2018;29:556561.

58. Shashikumar SA, Huang K, Konetzka RT, et al. Claims-based frailty indices: a systematic review. Med Care 2020;58:815-825

59. Kim DH, Patorno E, Pawar A, et al. Measuring frailty in administrative claims data: comparative performance of four claims-based frailty measures in the U.S. Medicare data. J Gerontol A Biol Sci Med Sci 2020;75:1120-1125. 
Supplemental online content for:

\section{BBCIC Research Network Analysis of \\ First-Cycle Prophylactic G-CSF Use in Patients Treated With \\ High-Neutropenia Risk Chemotherapy}

Pamala A. Pawloski, PharmD, BCOP; Cara L. McDermott, PharmD, PhD; James H. Marshall, MPH; Vanita Pindolia, PharmD, MBA; Catherine M. Lockhart, PharmD, PhD; Catherine A. Panozzo, PhD; Jeffrey S. Brown, PhD; and Bernadette Eichelberger, PharmD

J Natl Compr Canc Netw, doi: 10.6004/jnccn.2021.7027

eAppendix 1: List of NDCs and HCPCS Codes Used for G-CSF Exposures in Patients With Breast or Lung Cancer eAppendix 2: ICD-9-CM, CPT, and LOINC Codes Used to Identify Secondary Outcomes of G-CSF Use in Breast or Lung Cancer

eAppendix 3: Covariates With Potential Impact on Receipt or Outcomes Associated With G-CSF Prophylaxis in Breast or Lung Cancer 


\begin{tabular}{|c|c|c|}
\hline Medication & Code & Code Type \\
\hline Filgrastim & 54868252200 & NDC \\
\hline Filgrastim & 54868252201 & NDC \\
\hline Filgrastim & 54868502000 & NDC \\
\hline Filgrastim & 55513020901 & NDC \\
\hline Filgrastim & 55513020910 & NDC \\
\hline Filgrastim & 55513020991 & NDC \\
\hline Filgrastim & 55513034701 & NDC \\
\hline Filgrastim & 55513053001 & NDC \\
\hline Filgrastim & 55513053010 & NDC \\
\hline Filgrastim & 55513054601 & NDC \\
\hline Filgrastim & 55513054610 & NDC \\
\hline Filgrastim & 55513092401 & NDC \\
\hline Filgrastim & 55513092410 & NDC \\
\hline Filgrastim & 55513092491 & NDC \\
\hline Filgrastim & $\mathrm{J} 1440$ & HCPCS \\
\hline Filgrastim & J1441 & HCPCS \\
\hline Tbo-filgrastim & 61314030401 & NDC \\
\hline Tbo-filgrastim & 61314030410 & NDC \\
\hline Tbo-filgrastim & 61314031201 & NDC \\
\hline Tbo-filgrastim & 61314031210 & NDC \\
\hline Tbo-filgrastim & 63459091011 & NDC \\
\hline Tbo-filgrastim & 63459091015 & NDC \\
\hline Tbo-filgrastim & 63459091017 & NDC \\
\hline Tbo-filgrastim & 63459091036 & NDC \\
\hline Tbo-filgrastim & 63459091211 & NDC \\
\hline Tbo-filgrastim & 63459091212 & NDC \\
\hline Tbo-filgrastim & 63459091215 & NDC \\
\hline Tbo-filgrastim & 63459091217 & NDC \\
\hline Tbo-filgrastim & 63459091236 & NDC \\
\hline Tbo-filgrastim & J1446 & HCPCS \\
\hline Tbo-filgrastim & J1447 & HCPCS \\
\hline
\end{tabular}

Abbreviations: G-CSF, granulocyte colony-stimulating factor; NDC, National Drug Code. 


\section{eAppendix 2. ICD-9-CM, CPT, and LOINC Codes Used to Identify Secondary Outcomes of G-CSF Use} in Breast or Lung Cancer

\begin{tabular}{|c|c|c|c|}
\hline Outcome & ICD-9-CM Code & CPT Code & LOINC \\
\hline $\begin{array}{l}\text { Severe neutropenia defined by } \\
\text { absolute neutrophil count }\end{array}$ & & & $\begin{array}{l}\text { L0032013010104, } \\
\text { L0032013010110, } \\
\text { L0032013010204, } \\
\text { L0032013010210, } \\
\text { L0032013010304, } \\
\text { L0032013010310, } \\
\text { L0032013010404, } \\
\text { L0032013010410, } \\
\text { L0032013010504, } \\
\text { L0032013010510, } \\
\text { L0032013020104, } \\
\text { L0032013020110, } \\
\text { L0032013020204, } \\
\text { L0032013020210, } \\
\text { L0032013020304, } \\
\text { L0032013020310, } \\
\text { L0032013020404, } \\
\text { L0032013020410, } \\
\text { L0032013020504, } \\
\text { L0032013020510, } \\
\text { L0032013070104, } \\
\text { L0032013070110, } \\
\text { L0032013070204, } \\
\text { L0032013070210, } \\
\text { L0032013070304, } \\
\text { L0032013070310, } \\
\text { L0032013070404, } \\
\text { L0032013070410, } \\
\text { L0032013070504, } \\
\text {,0032013070510 }\end{array}$ \\
\hline Anaphylaxis & $\begin{array}{l}995.2,995.20,995.27,995.29 \\
995.3,995.6 \times, 995.7,995.0,999.49\end{array}$ & & \\
\hline Bone pain & $\begin{array}{l}\text { 730. } \times, 733.0 \times, 733.1 \times-733.9 \times \\
\text { E934. } \times, \text { E947. } \times\end{array}$ & & \\
\hline Hyperleukocytosis & $288.3,288.4,288.6,288.8,288.9$ & & \\
\hline $\begin{array}{l}\text { Combined: glomerulonephritis, } \\
\text { capillary leak syndrome, splenic } \\
\text { rupture }\end{array}$ & $\begin{array}{l}580 . \times, 582 . \times, 448.9,865.0,865.1 \\
865.10,865.12,865.13,865.14 \\
865.19\end{array}$ & $38100,38101,38102,38815$ & \\
\hline
\end{tabular}

Abbreviation: G-CSF, granulocyte colony-stimulating factor; LOINC, Logical Observation Identifiers Names and Codes. 


\section{eAppendix 3. Covariates With Potential Impact on Receipt or Outcomes Associated With G-CSF Prophylaxis in Breast or Lung Cancer}

Combined comorbidity score

Anaphylaxis

Anemia

Arthritis

Bone pain

Bone marrow/stem cell transplant

Cancer-related radiation

Capillary leak syndrome

Congestive heart failure

Chronic obstructive pulmonary disease

Glomerulonephritis

HIV/AIDS

Hyperleukocytosis

Kidney disorder

Latex allergy

Severe liver impairment

Lumpectomy/Mastectomy

Metastatic bone cancer

Metastatic brain cancer
Metastatic liver cancer Metastatic disease

Neutropenia

Peptic ulcer disease

Poor nutritional status

Second cancer diagnosis

Splenic rupture

Recent surgery/wounds

Thyroid disorder

Chemotherapy regimens of interest ${ }^{a}$

Antibiotics

Endocrine drug products

Drug therapy for bone metastases (eg, bisphosphonates, denosumab)

Breast chemotherapy (regimen of interest) [breast cohort only]

Other breast chemotherapy [breast cohort only]

Other chemotherapy (not breast) [breast cohort only]

Small cell lung cancer chemotherapy (regimen of interest) [small cell lung cancer cohort only] Other small cell lung chemotherapy [small cell lung cancer cohort only]

Other chemotherapy (not lung) [small cell lung cancer cohort only]

Abbreviation: G-CSF, granulocyte colony-stimulating factor.

${ }^{a}$ Reported in Renner P, Milazzo S, Liu JP, et al. Primary prophylactic colony-stimulating factors for the prevention of chemotherapy-induced febrile neutropenia in breast cancer patients. Cochrane Database Syst Rev 2012;10:CD007913. 